\title{
Trends in fertility and fertility preferences in sub-Saharan Africa: the roles of education and family planning programs
}

John Bongaarts

\author{
Correspondence: jbongaarts@ \\ popcouncil.org \\ Population Council, 1 Dag \\ Hammarskjold Plaza, New York, NY \\ 10017, USA
}

\begin{abstract}
A common explanation for the high fertility prevailing in sub-Saharan Africa (SSA) is a widespread desire for large families. This situation poses a challenge to population policy-makers in the continent. If the desired family size is high, then presumably family planning programs can only have a limited effect on fertility because these programs aim to assist women in achieving their reproductive goals. But this conclusion is based on the assumption that family planning programs do not affect the desired family size, which is questionable and is investigated here. This study examines the determinants of trends wanted and unwanted fertility in SSA using fixed-effects regressions of country-level data. The dependent variables include the total fertility rate, and its wanted and unwanted components. Explanatory variables include a family planning program score and four socioeconomic variables (women's educational attainment, child mortality, GNI per capita, and percent urban). Data come from 103 DHS surveys in 25 countries in SSA with at least two DHS surveys between 1989 and 2019. Women's education and family planning programs are found to be the dominant determinants of fertility decline and their effects operate by reducing both wanted and unwanted fertility. The effects of education are not surprising but the finding that family planning programs can reduce wanted fertility implies that their impact can be larger than conventional wisdom suggests. Indeed, in a few poor countries, the implementation of high-quality programs has been associated with substantial declines in wanted fertility (e.g., Ethiopia, Malawi, Rwanda). The mechanism through which this effect operates is unclear but likely involves media programs that diffuse knowledge about the benefits of smaller families.
\end{abstract}

\section{Introduction}

After decades of rapid demographic change, most countries of the world are now at or close to the end of their demographic transitions with fertility at or below replacement. The only exception to this generalization is sub-Saharan Africa (SSA) where fertility and population growth remain high. The UN estimates the total fertility rate (TFR) of sub-Saharan Africa at 4.7 births per woman in 2015-2020, more than twice the level of any other world region. As a result, the population of the continent is expected to grow from 1 billion in 2015 to more than 2 billion in 2050 and nearly 4 billion in 2100

(c) The Author(s). 2020 Open Access This article is licensed under a Creative Commons Attribution 4.0 International License, which permits use, sharing, adaptation, distribution and reproduction in any medium or format, as long as you give appropriate credit to the original author(s) and the source, provide a link to the Creative Commons licence, and indicate if changes were made. The images or other third party material in this article are included in the article's Creative Commons licence, unless indicated otherwise in a credit line to the material. If material is not included in the article's Creative Commons licence and your intended use is not permitted by statutory regulation or exceeds the permitted use, you will need to obtain permission directly from the copyright holder. To view a copy of this licence, visit http://creativecommons.org/licenses/by/4.0/. 
(United Nations, 2019). This massive expansion of human numbers will likely have a range of adverse effects on human welfare and the environment.

The situation of SSA in the 1990s was not unlike that of Asia and Latin America in the 1960s: fertility was high, mortality had declined substantially, population growth was rapid, and socioeconomic indicators were low but improving. Despite these similarities, SSA in the 2000s did not follow the path of rapid fertility decline observed in Asian and Latin American countries in the 1970s and 1980s. Fertility declines in SSA over the past two decades have been slow and in several countries, fertility has stalled (Bongaarts, 2008; Schoumaker, 2019). The UN projects a slower future fertility transition in the SSA than in the 70s in Asia and Latin America (United Nations, Population Division, 2019).

Why has the SSA fertility transition been so late and slow? In a classic study, (Caldwell and Caldwell, 1988) examine this question and conclude: "The explanation is a lack of African demand for limiting family size, the result of family structures and economies quite different from Asia, and of essentially religious attitudes toward fertility that have an impact both on family economics and the acceptability of various forms of fertility control (p.19)." This conclusion is supported by survey estimates of the desired family size which have consistently shown higher preferences in SSA then elsewhere in the developing world (Lightbourne, 1987; Westoff, 2010).

These findings pose a challenge to population policy-makers in SSA. If the desired family size is high, then presumably family planning (FP) programs can only have a limited effect on fertility because these programs aim to assist women in achieving their reproductive goals. But this conclusion is based on the assumption that FP programs do not affect the desired family size and only provide women with access to and information about contraception to reduce unplanned birth. However, in this study, I will demonstrate that these programs go beyond addressing an unmet need for contraception and also can reduce wanted fertility. As a result, the impact of FP programs can be substantially larger than conventional wisdom suggests. Indeed, as will be shown below, in a few countries in sub-Saharan Africa the implementation of high-quality programs has been associated with rapid changes in reproductive behavior.

This study first summarizes key findings from the literature on the determinants of fertility and the fertility impact of FP programs. Next, data and methods are described. The results section presents new estimates of the effect of FP programs on fertility and its wanted and unwanted components in SSA. The discussion puts the findings in the context of earlier literature.

\section{Background}

A large literature examines the causes of fertility decline in the developing world over the past half-century. This literature is not easily summarized, but there is broad agreement that development is a key driver of changes in reproductive behavior, as hypothesized by classical demographic transition theory (Davis, 1945; Kirk, 1996; Notestein, 1945). Which dimension of development is most important remains a matter of some debate, although ample evidence now indicates that improvements in female education and women's empowerment are dominant (Cochrane, 1979; Gaylor, 2005; Hadden \& London, 1996; Jejeebhoy, 1995; Kravdal, 2002; Lloyd, 2003; Lutz \& Skirbekk, 2014; May \& Rotenberg, 2020; Murtin, 2013; Schultz, 1994; Summers, 1992a, 1992b). A 
comprehensive regression analysis of the determinants of fertility using long time series of data concludes "..average years of primary schooling among the adult population, rather than income standards, child mortality, or total mortality rates, drive fertility down by about $40 \%$ to $80 \%$ when those years grow from zero (no illiteracy) to 6 years (full literacy). This result is robust to a variety of specifications, samples, and econometric models.." (Murtin, 2013). Similarly, Lutz and Skirbekk (2014) conclude “...educational attainment is not just one of many socio-economic factors that matter ..[it] is the single most important source of empirically observable population heterogeneity." Several causal forces have been proposed for the effect of women's education on both wanted and unwanted fertility, including greater autonomy in decision making, more knowledge about the reproductive process and contraception, higher potential for earnings, and rising opportunity costs of childbearing (Diamond, Newby, \& Varle, 1999; Jejeebhoy, 1995; Lloyd, 2003).

There is much less agreement about the fertility impact of FP programs which have been widely implemented in the developing world since the 1960s. Proponents of family planning have provided a solid rationale for such programs by demonstrating that substantial proportions of women have an unmet need for contraception and that this unmet need leads to many unplanned pregnancies and abortions (Casterline \& Sinding, 2000; Freedman \& Berelson, 1976; Singh, Darroch, \& Ashford, 2014; Tietze, 1981). In countries that implemented high-quality programs, contraceptive use rose and fertility fell, sometimes sharply (Robinson \& Ross, 2007). In addition, experiments such as the one in the Matlab district of Bangladesh demonstrated a substantial uptake of contraception in the intervention population (Cleland, Phillips, Amin, \& Kamal, 1994; Phillips, Stinson, Bhatia, Rahman, \& Chakraborty, 1982). This evidence persuaded many governments to implement programs and international donors provided massive funding. A review of the evidence by the World Bank in the early 1990s concluded that family planning programs had succeeded in many countries and should be expanded (World Bank, 1993).

Critiques of FP programs appeared soon after they were introduced. For example, Davis (1967) and Demeny (1975) argued that these programs could not have a significant impact on reproductive behavior because of a lack of demand for their services. One of the most influential critiques was offered by Lant Pritchett (1994). He made a new contribution to the debate by examining wanted and unwanted fertility separately. Based on a cross-sectional analysis, he concluded that fertility declines were largely driven by declines in wanted fertility and that declines in unwanted fertility were not important. In his view, this lack of a decline in unwanted fertility demonstrated that FP programs played little or no role in fertility transitions. He dismissed the experimental evidence from Matlab as being too expensive for implementation in large populations.

Responses to the Pritchett critique pointed to several problemswith his analysis. Bongaarts (1997) noted that unwanted fertility would have gone up over time in the absence of contraceptive use because with declining wanted fertility women are exposed to the risk of unplanned pregnancies during increasing proportions of their reproductive years. FP programs, therefore, affect overall fertility by preventing a rise in unwanted fertility. A further critique can be found in Lam (2011) who points out that the cross-sectional approach is potentially problematic and demonstrated that trend 
analysis gives very different results. According to Lam, half of fertility declines in the developing world are attributable to declines in unwanted fertility. Lam does not attempt to assess directly the role of FP programs but notes that they may well have been one of the causes of these declines.

More recently, Günther and Harttgen (2016) expanded on the work of Pritchett and Lam using fixed-effects regression models to control for confounding country effects. They also found substantial declines in unwanted fertility over time, but this effect is largely confined to non-Africa countries. The effect of FP programs was significant but modest.

Any study of the impact of FP programs must have an accurate country-level indicator of program strength. As noted by Guenter and Hartgen, a central problem that has plagued many earlier evaluation studies is the possibility of errors in the measurement of FP effort. The oldest and most widely used indicator is the family planning program effort (FPPE) score, a measure used since the early 1970s to gauge the strength of national programs (Kuang \& Brodsky, 2016; Mauldin \& Ross, 1991; Ross \& Smith, 2011). To obtain this score, knowledgeable observers in each country answer questions about a variety of program characteristics and policy actions. Their responses are combined to yield an overall FPPE score. Over the past three decades, the FPPE score for countries has been measured in eight cycles ending in 2014. However, the FPPE score suffers from some shortcomings. Differences between countries and across cycles can occur simply because the experts often must make subjective assessments and the experts change over time. In addition, the questions used to create the index have been refined and changed over time. As a result, differences between FPPE scores of countries and trends for individual countries should be interpreted with caution.

Günther and Harttgen (2016) call for further research on this topic. This call was answered by Bongaarts and Hardee (2017) who developed a FP program indicator called "public-sector family planning program impact score" to measure the quality and scope of the government's public family planning program. The index can be consistently measured over time in countries with standard Demographic and Health (DHS) surveys and it does not rely on subjective assessments. This score ranges from 0 in the absence of a government program to a theoretical value of 100 for the best public programs where all demand for contraception is met by the public sector. For simplicity, this variable will be referred to as the "program score" (PS).

The present study builds on and extends this earlier work in two ways: (1) it uses the new PS indicator to assess family planning programs, and (2) it examines the effect of FP programs on wanted and unwanted fertility separately. The latter is important because Pritchett, Lam, and Guenter take for granted that FP programs operate solely on unwanted fertility and that wanted fertility is determined by socio-economic development. As will be demonstrated below, this assumption is too limited and, as a result, past studies have underestimated program effects on fertility.

\section{Data and methods}

This study examines the determinants of trends in fertility and its wanted and unwanted components in SSA using regression analysis of country-level data. The dependent variables included are (1) the total fertility rate (TFR), (2) the wanted total fertility rate (WTFR), and (3) the unwanted total fertility rate (UWTFR). Estimates of 
TFR and WTFR of countries in SSA are obtained from the DHS online databank and the UWTFR is estimated as the difference between the TFR and WTFR (ICF International, 2020). The WTFR are estimated in the same way as the standard TFR, except that births are excluded if they occurred after the woman's desired family size has been reached. This procedure is used in all Demographic and Health surveys (Rutstein \& Rojas, 2006), but it can be subject to potential biases. Bongaarts (1990) and Casterline and El-Zeini (2007) propose alternative methods for estimating the WTFR, but these methods are more complex and not widely used. For present purposes, I will rely on the conventional WTFR, because on average the difference between it and the two alternatives is less than 0.1 births per woman in SSA (Günther \& Harttgen, 2016).

The explanatory variables consist of the family planning score, PS, and the following socioeconomic variables: (1) education as measured by the average years of schooling among women aged 20-39 (women's educational attainment), (2) child mortality (ages 0-4), (3) GNI per capita (PPP), and (4) percent of population that is urban. The education estimates are taken from the Wittgenstein Center for Demography and Global Human Capital (2020) and estimates of child mortality, GNI per capita, and percent urban are taken from the World Bank Development Indicators database (2020). The family planning score PS is calculated from DHS survey information with an equation described by Bongaarts and Hardee (2017).

Country-level data come from 104 DHS surveys in 25 countries in SSA with at least two DHS surveys between 1989 and 2019 (i.e., Benin, Burkina Faso, Burundi, Cameroon, Chad, Congo Democratic Republic, Cote d'Ivoire, Ethiopia, Ghana, Guinea, Kenya, Madagascar, Malawi, Mali, Mozambique, Niger, Nigeria, Rwanda, Senegal, Sierra Leone, South Africa, Tanzania, Uganda, Zambia, Zimbabwe) covering 89.3\% of the population of SSA. Only countries with a population size above 5 million in 2015 are included because many smaller countries have high international migration levels which affect reproductive behavior. The exclusion of smaller populations also makes the unweighted regional averages of indicators more representative of the continent and makes the figures easier to interpret. ${ }^{1}$ Fixed effects regression models are used to estimate the impact of PS and socioeconomic variables on the TFR, WTFR, and UWTFR. By using countries as their own controls, fixed effects models account for time-stable differences among countries, which may otherwise introduce bias into parameter estimation.

\section{Results}

\section{Levels and trends}

Table 1 presents the (unweighted) mean values of the dependent and explanatory variables measured at the time of the first and last available surveys in the 25 countries included in this study. The average years of the first and last surveys were 1996.1 and 2014.4 respectively. During this nearly two-decade interval, the means of the three fertility indicators declined: from 5.8 to 5.1 births per woman in the TFR, from 4.9 to 4.4 birth per woman in the WTFR, and from 0.9 to 0.7 births per woman in the UWTFR. The overall fertility decline of 0.7 birth per woman is therefore the result of a decline

${ }^{1}$ Also excluded are the following surveys with special conditions: Burkina Faso 2003 (coding of traditional methods is not standard), Etiopia 2000 (war with Eritrea), Mozambique 2003 (massive floods), and Rwanda 2000 (massive refugee flows in aftermath of civil war and wars with neighboring countries). 
Table 1 Mean values (unweighted) of the dependent and explanatory variables at the time of the first and last DHS survey, 25 countries in sub-Saharan Countries

\begin{tabular}{lll}
\hline & First survey & Last survey \\
\hline Survey year & 1996.1 & 2014.4 \\
Dependent variables & & 5.1 \\
TFR (births per woman) & 5.8 & 4.4 \\
WTFR & 4.9 & 0.7 \\
UWTFR & 0.9 & \\
Explanatory variables & & 5.3 \\
Education (years) & 3.3 & 81.1 \\
Child mortality (per 1000) & 161.9 & 3.3 \\
GNI/cap (PPP) log & 3.0 & 34.8 \\
Percent urban & 27.4 & 33.1 \\
Program score & 14.0 & 25 \\
$N$ & 25 & \\
\hline
\end{tabular}

of 0.5 births per woman in the WTFR and a decline of 0.2 births per woman in the UWTFR. The average pace of decline (measured in births per woman per year) is 0.038 for the TFR and 0.029 and 0.010 for the WTFR and UWTFR, respectively. Declines in wanted fertility dominate declines in unwanted fertility. Also shown in Table 1 are the mean values of the four socio-economic indicators which all moved to expected direction, i.e., increases in education, GNI per capita and percent urban, and declines in child mortality. The program score increased substantially from very low levels in the 1990s.

These averages conceal considerable variation in levels and trends at the country level. Figure 1 plots trends in the TFR for individual countries. In many countries, fertility changed little and only a few show substantial declines. The highest recent TFRs are found in Niger and Mali and the lowest in South Africa and Kenya. The highest pace of decline

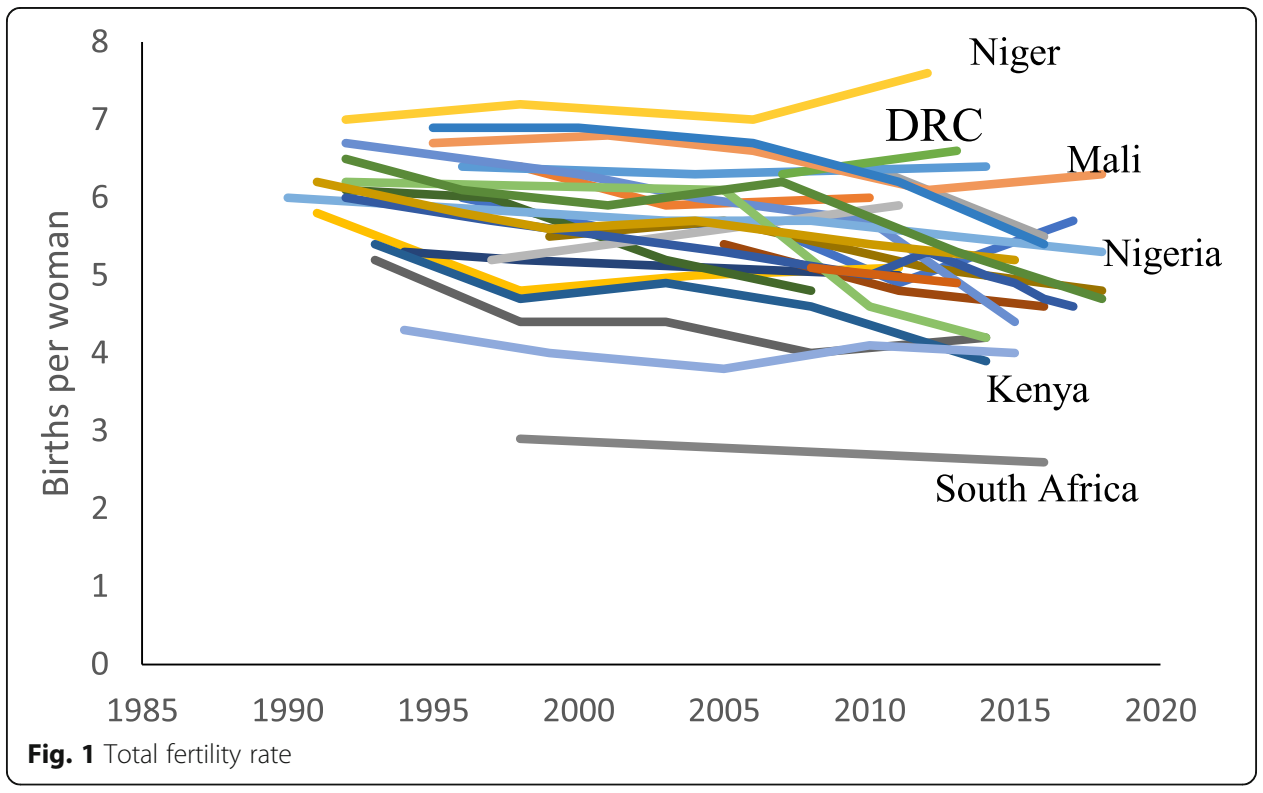




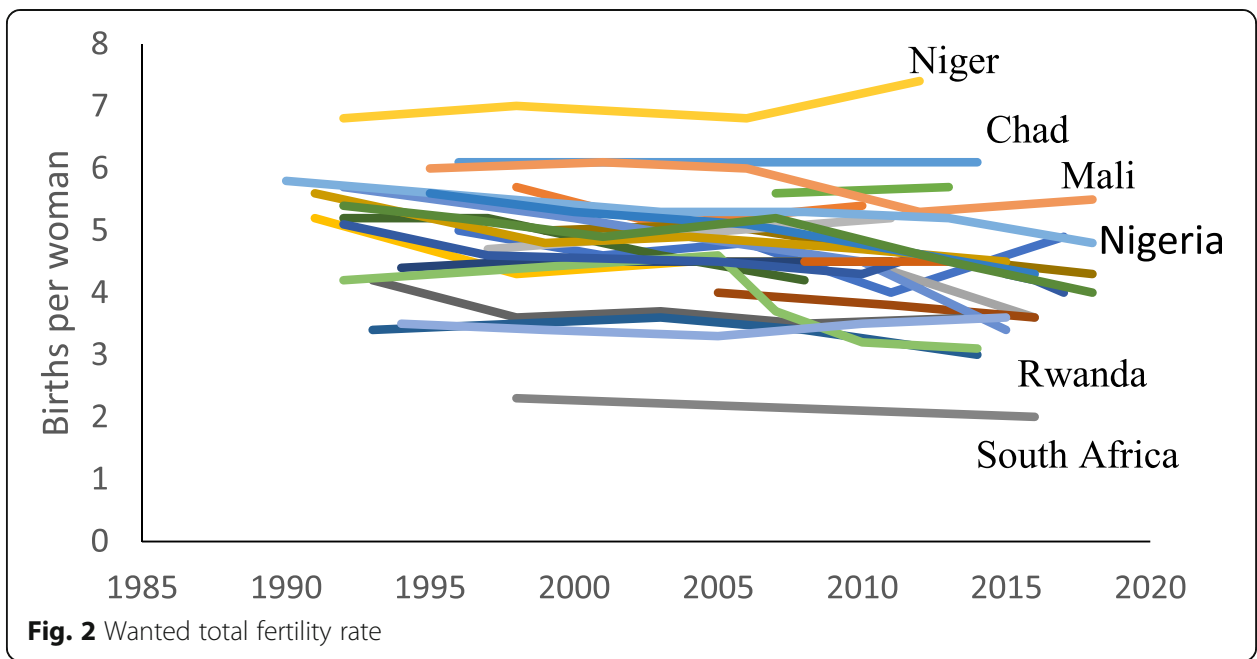

(above 0.07) occurred in Burundi, Ethiopia, Madagascar, Malawi, Rwanda, and Uganda. Fertility increased slightly in Congo and Niger. As shown in Fig. 2, trends in the WTFR closely follow the pattern of the TFR although at a somewhat lower level. Figure 3 plots UWTFR trends (note the different scale of the vertical axis). Little systematic patterns emerge except for a small decline on average. There is a statistically significant inverse relationship between UWTFR and WTFR which implies that countries with high WTFR tend to have lower UWTFR (e.g., Mali and Chad).

\section{Correlations}

Figure 4 provides a first look at the relationship between socioeconomic variables and fertility by plotting the TFR by the mean years of schooling of women aged 20-39. The figure contains 25 markers, one for each of 25 countries, representing observations at the most recent survey (ca. 2014). The size of the round marker is proportional to the

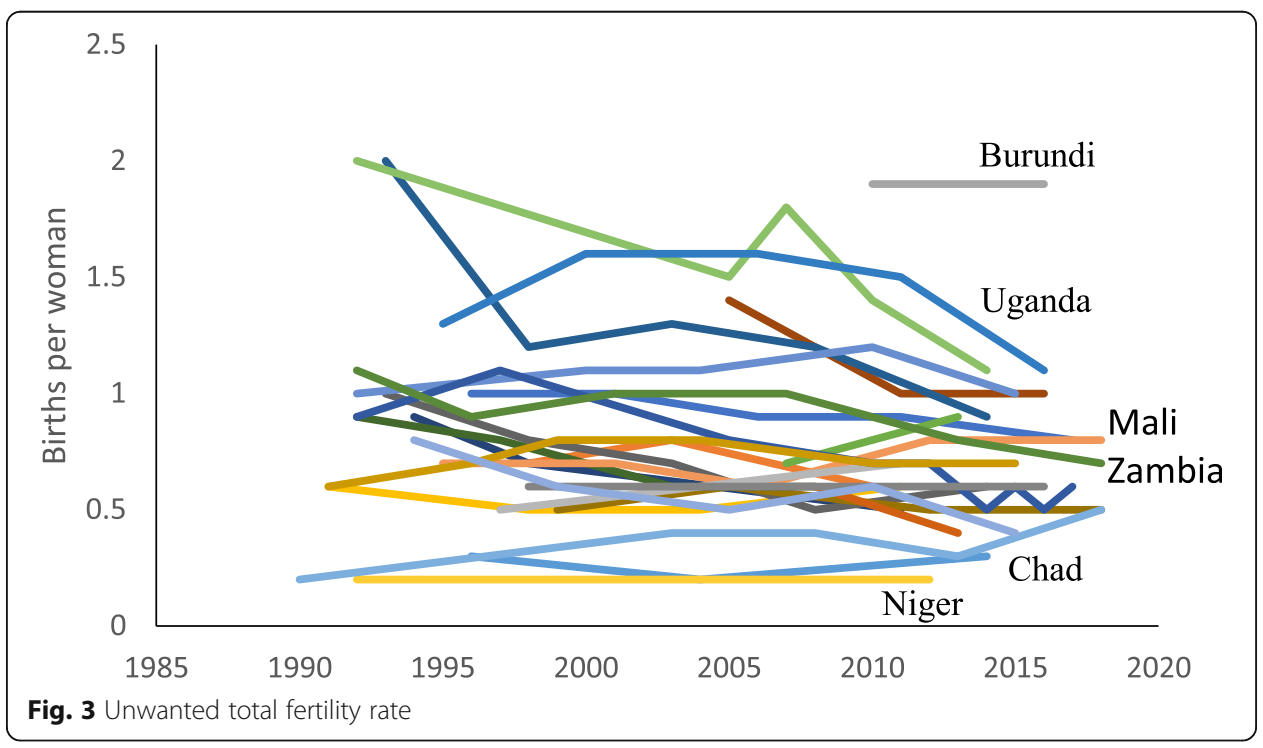




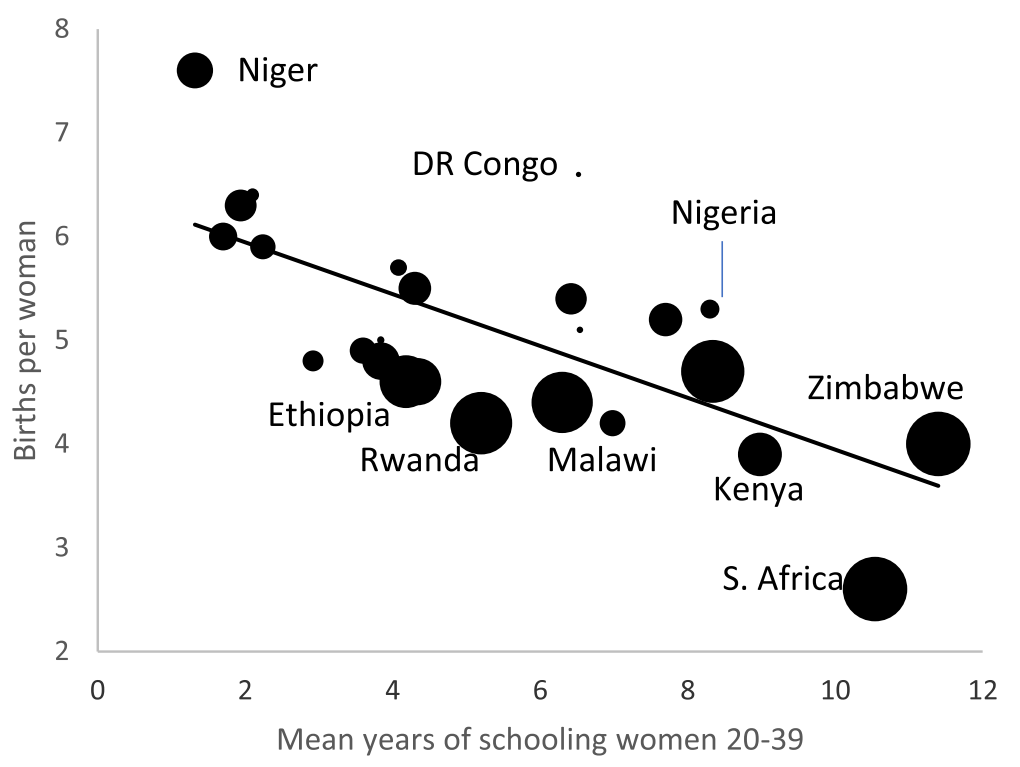

Fig. 4 Total fertility rate by level of education and program score, 25 countries in sub-Saharan Africa

program score of the country which ranges from 5 in DR Congo to 62 in South Africa and Zimbabwe.

If female education were the only determinant of the TFR, then the observations for all countries would fall on a single line. This is not the case, indicating an impact of FP programs and other factors. In general, the higher the level of women's educational attainment, and the higher the program score, the lower the TFR. At any level of women's educational attainment, fertility varies widely. For example, in the countries with schooling levels between 6 and 7 years, fertility ranges from 6.6 births per woman in DR Congo to 4.4 in Malawi. As will be shown below, the differences among countries with similar levels of women's educational attainment are mostly due to program differences. The findings in Fig. 4 suggest that education and program score both have a substantial effect on fertility, but quantifying these effects requires formal regression analysis.

\section{Regressions}

Panel A in Table 2 summarizes the regression results for the TFR. The full model includes all five explanatory variables. The coefficients for education and program score are statistically significant $(P<0.05)$, while the coefficients for child mortality, percent urban and GNI per capita are not. The reduced model drops these non-significant variables and again confirms that women's education and family planning programs have a highly significant impact on fertility.

Panels B and C in Table 2 summarize the regression results for the WTFR and UWTFR. The reduced models show a significant negative effect of program score on WTFR and UWTFR. Women's education has a significant negative effect on WTFR but not on UWTFR. The education coefficient for the TFR $(-0.127)$ equals the sum of the coefficients for the WTFR $(-0.087)$ and UWTFR $(-0.040)$. The TFR effect of education is therefore $69 \%$ due to the WTFR effect and $31 \%$ to the UWTFR effect. 
Table 2 Results of fixed effects regression models of fertility, wanted fertility and unwanted fertility on socioeconomic variables and program score in 25 Sub-Saharan Africa countries with 104 DHS surveys

\begin{tabular}{|c|c|c|c|c|c|}
\hline \multicolumn{3}{|l|}{ Full model } & \multicolumn{3}{|l|}{ Reduced model } \\
\hline \multicolumn{6}{|c|}{ Panel A: Total fertility rate } \\
\hline & Coefficient & $P$ value & & Coefficient & $P$ value \\
\hline Education & -0.139 & 0.043 & Education & -0.127 & 0.005 \\
\hline Child mortality & -0.003 & 0.063 & Program score & -0.026 & 0.000 \\
\hline GNI/cap & 0.216 & 0.736 & & & \\
\hline Percent urban & -0.023 & 0.186 & & & \\
\hline Program score & -0.033 & 0.000 & & & \\
\hline Constant & 7.29 & 0.000 & Constant & 6.63 & 0.000 \\
\hline N & 104 & & $\mathrm{~N}$ & 98 & \\
\hline$R^{2}$ within & 0.67 & & $R^{2}$ within & 0.64 & \\
\hline \multicolumn{6}{|c|}{ Panel B: Wanted total fertility rate } \\
\hline & Coefficient & $P$ value & & Coefficient & $P$ value \\
\hline Education & -0.068 & 0.288 & Education & -0.087 & 0.035 \\
\hline Child mortality & -0.002 & 0.224 & Program score & -0.021 & 0.000 \\
\hline GNI/cap & 0.212 & 0.723 & & & \\
\hline Percent urban & -0.025 & 0.125 & & & \\
\hline Program score & -0.026 & 0.000 & & & \\
\hline Constant & 5.89 & 0.001 & Constant & 5.52 & 0.000 \\
\hline N & 104 & & $\mathrm{~N}$ & 98 & \\
\hline$R^{2}$ within & 0.58 & & $R^{2}$ within & 0.56 & \\
\hline \multicolumn{6}{|c|}{ Panel C: Unwanted total fertility rate } \\
\hline & Coefficient & $P$ value & & Coefficient & $P$ value \\
\hline Education & -0.072 & 0.048 & Education & -0.040 & 0.079 \\
\hline Child mortality & -0.001 & 0.168 & Program score & -0.005 & 0.019 \\
\hline GNI/cap & 0.004 & 0.991 & & & \\
\hline Percent urban & 0.002 & 0.822 & & & \\
\hline Program score & -0.008 & 0.009 & & & \\
\hline Constant & 1.40 & 0.160 & Constant & 1.10 & 0.000 \\
\hline N & 104 & & N & 98 & \\
\hline$R^{2}$ within & 0.29 & & $R^{2}$ within & 0.26 & \\
\hline
\end{tabular}

Similarly, the TFR effect of program score is $81 \%$ due to the WTFR effect and $19 \%$ due to the UWTFR effect.

The absolute country-level fertility effects of women's schooling and the FP program can be estimated by multiplying the regression coefficients in the reduced model by the observed values of the two explanatory variables. Figure 5 plots the resulting fertility effects in each country at the time of the latest DHS survey. The program impact exceeds 1 birth per woman in Ethiopia, Kenya, Malawi, Rwanda, Senegal, South Africa, Zambia, and Zimbabwe, and reaches 1.55 in Malawi, 1.57 in Rwanda, 1.62 in Zimbabwe, and 1.63 in South Africa, the four countries with the highest program scores. The education effect exceeds 1 birth per woman in Kenya, Nigeria, Zambia, Zimbabwe, and South Africa. The average program effect $(0.83$ 


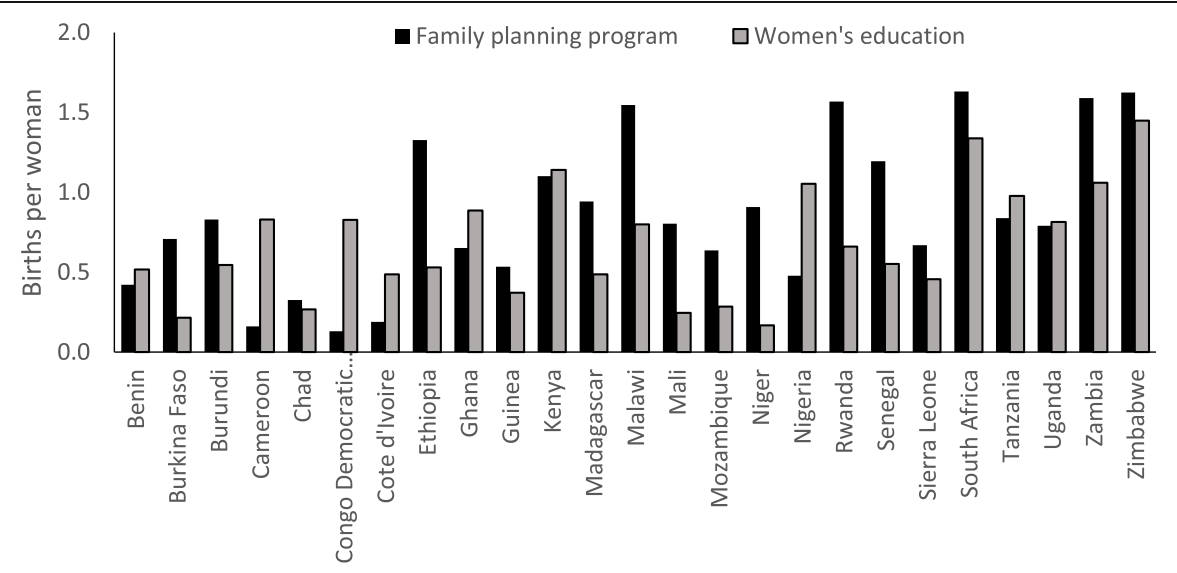

Fig. 5 Model estimates of education and program effects on TFR, year of latest survey

births per woman) is slightly larger than the average education effect (0.65 births per woman).

\section{Discussion}

The regressions show some expected results but also have some surprises. The finding that education is the main socioeconomic determinants of fertility decline is consistent with the past literature (see discussion above) and hence not surprising. However, the results for the effect of the FP program score deserve further comment.

Past evaluations of FP programs have found their impact on contraceptive use and fertility to be substantial. Three different approaches have been used to obtain impact estimates.

\section{Controlled experiments}

This is the gold standard for evaluating interventions, but very few large-scale controlled experiments have been conducted to assess family planning programs because they are expensive and take a long time to complete. The largest and most influential of these experiments-the Family Planning and Health Services Project (FPHSP)started in the late 1970s in Matlab, a rural district in Bangladesh (Cleland et al., 1994; Phillips et al., 1982). At that time, Bangladesh was one of the poorest and most highly agricultural countries in the world, and there was widespread skepticism that family planning would be accepted in such a traditional society. The FPHSP divided the Matlab district (population of 173,000 in 1977) into experimental and control areas of approximately equal size. The control area received the same very limited services as the rest of the country, while in the experimental area comprehensive high-quality family planning services were provided aimed at reducing the costs (monetary, social, psychological, and health) of adopting contraception. The experimental area provided free services and supplies of a range of methods (pills, condoms, injectables, IUD, and sterilization), home visits by well-educated female family planning workers, regular follow-up to address health concerns, comprehensive multimedia communication, and menstrual regulation services. Outreach to husbands, bari leaders, and religious leaders addressed potential social and familial objections from men. 
The impact of the new family planning services was large and immediate. Within 2 years, contraceptive use jumped from 5 to 33\% among women in the experimental area while little change occurred in the control area (Cleland et al., 1994; Phillips et al., 1982). As a result, fertility declined more rapidly in the experimental than in the control area and a difference of around 1.5 births per woman between the areas was maintained through the 1980s until the services in the rest of the country were also improved. The Matlab experiment demonstrated that family-planning programs can succeed even in highly traditional societies. A similar but more complex experiment conducted in the Navrongo district of Northern Ghana in the 1990s led to a decline in fertility of 1.0 births per woman (Debpuur et al. 2002).

\section{Natural experiments}

Natural experiments, which compare two countries with similar social, economic, cultural, and religious characteristics-but with differing approaches to family planning programs-also demonstrate the impact of voluntary family planning (Bongaarts, Cleland, Townsend, Bertrand, \& Das Gupta, 2012; Cleland, 1994; Lee, Lush, Walt, \& Cleland, 1998).

An instructive example is a comparison of Bangladesh and Pakistan, which were one country from 1947 until Bangladesh became independent after the civil war in 1971. These two populations had similar cultures and levels of social and economic development. However, the countries differed in their commitment to family planning after Bangladesh achieved independence. Pakistan's program remained weak and ineffective and lacked government funds and commitment (Cleland \& Lush, 1997). In contrast, after the success of the Matlab experiment, the government of Bangladesh implemented one of the world's most effective voluntary family-planning programs. A unique feature of the Bangladesh program is its cadre of literate female workers who counsel women and distribute supplies at the doorstep, overcoming barriers posed by Purdah customs which restrict women's movement outside the home. In addition, messages from an information and education program on radio and television emphasized the benefits of smaller families and contraception.

This high-quality program in Bangladesh is likely the main cause of different fertility trajectories of Bangladesh and Pakistan. In 1975-1980, the two countries had nearly the same high fertility of 6.8 births per woman, but trends diverged in subsequent decades. By the late 1990s, Bangladesh's fertility had declined to 3.4 births per woman, while in Pakistan, fertility stood at 5.4, a difference of 2 births per woman (United Nations, 2019).

Similar results hold for other country pairs: Iran and Jordan, Kenya and Uganda, and Indonesia and the Philippines. Fertility declined to substantially lower levels in countries with strong programs (Iran, Kenya, Indonesia) than in corresponding weak program countries (Jordan, Uganda, and the Philippines) (Bongaarts et al., 2012; Cleland, 1994; Lee et al., 1998)

\section{Regression analyses}

In the absence of experimental evidence, researchers have turned to country-level regression analysis to estimate the fertility effects of programs. In these regressions, 
fertility or contraceptive use are the dependent variables and a set of socio-economic indicators are the independent variables (Günther \& Harttgen, 2016; Lam, 2011; Pritchett, 1994; Bongaarts \& Hardee, 2019). In addition, an indicator of family planning program effort is used as a key explanatory variable. As noted, these past efforts have been hampered by potential inaccurate measurement of the program effort. This issue is addressed in the regressions presented above by using a new program score. The results show that the best programs can reduce fertility by about 1.5 births per woman. This estimate is close to the effects found in the Matlab and from the natural experiments.

The results from these three different estimation methods suggest a broad consensus on the TFR impact of a high-quality program, but the relative impact of programs on the wanted and unwanted components of fertility deserves a brief comment. Given the widely held assumption that programs only affect unwanted fertility, it is surprising to show that the program effect also has a substantial impact on wanted fertility (see Table 2). ${ }^{2}$ There are two reasons for this outcome.

First, most family planning programs do much more than providing access to contraceptive methods and services. In particular, they often undertake behavior change communication (BCC) activities to encourage the adoption of contraception and to raise awareness of the benefits of smaller families. BCC programs disseminate information via mass media, community-level events, interpersonal communication/counseling, and electronic media to provide information on types of contraceptive methods, safety, sources of supply, and management of side effects. They also discuss the wide-ranging social, health, economic, and environmental benefits of contraception and smaller families for women, families, and communities, which can lead to a decline in wanted fertility. Media communication programs can have a powerful influence on community norms, helping to shape perceptions about new behaviors and their acceptance by community members.

Program communication efforts often range beyond individuals and communities to reach policy-makers. Advocacy aims to influence the opinions and decisions of policymakers regarding laws, regulations, and other structural factors that affect contraceptive use. The support of the highest levels of policy-makers is essential to the success of family planning programs.

Second, while BCC activities can bring about changes in reproductive norms and thus explain the effect of programs on wanted fertility, they do not explain the relatively small effect of FP programs on unwanted fertility. This issue has been examined in earlier research (Bongaarts, 1997). In brief, FP programs do reduce unwanted fertility, but their effect is offset by a separate force that increases unwanted fertility as populations move through the fertility transition. This separate force results from an increase in the number of years that a woman is at risk of having an unwanted pregnancy as desired family size declines. In the least developed countries, fertility is high in part because women want relatively large families. To achieve this goal, women bear children for most of their reproductive years, thus leaving little time for exposure to unplanned pregnancies. In contrast, in more developed countries, with desired family sizes near two, women can complete their desired childbearing in a few years and then face many

${ }^{2}$ Bongaarts (2011) presents evidence that FP programs can reduce desired family size. 
years of risk to unintended pregnancy. For example, suppose a woman wants and has two births, say at ages 20 and 22, and did not have pregnancies before age 20. From age 22 onward, this woman then faces approximately two decades of fecund years during which she does not want to get pregnant in any of the remaining 260 menstrual cycles. To ensure no unplanned pregnancies occur, women must practice $100 \%$ effective contraceptive use during every menstrual cycle in which they are sexually active until menopause is reached. This outcome is difficult to achieve, and many women do not use fully effective contraception all the time when they want to avoid pregnancies. Consequently, unwanted fertility would rise substantially over time in the absence of contraception. In reality, this rise only happens in countries with weak FP programs. In other countries, this rise is avoided or more than offset by rising contraceptive use aided by FP programs. Hence, the modest net impact of FP programs on unwanted fertility.

\section{Conclusion}

The high desired family size widely observed in sub-Saharan Africa is an obstacle to rapid fertility decline. However, the preceding analysis indicates that women's education and family planning programs can reduce wanted fertility. This effect of education is not surprising and has been well established in the literature, but the effect of FP programs is contrary to the conventional view of these programs.

FP programs are often justified by the existence of high levels of unmet need and unplanned pregnancies which provides a powerful rationale for such investments. However, even if all unwanted fertility could be removed in SSA, fertility would remain relatively high because most women want large families. The results of the above regression analyses demonstrate that FP programs do more than reduce unplanned pregnancies: they also have a substantial effect on wanted fertility. The precise mechanism through which this effect operates is not investigated here but likely involves behavioral change programs that diffuse knowledge about the benefits of smaller families.

Investments in FP programs have remained weak in many SSA countries in part because policy-makers often believe that these programs cannot work or have only a minor effect in settings with limited demand for birth limitation. This view is incorrect because several poor countries in SSA have implemented good programs (e.g., Ethiopia, Malawi, Rwanda) with considerable success which is in large part due to their impact on wanted fertility. Other countries with weak programs should follow the example of their successful neighbors by implementing better integrated policies addressing family planning and reproductive health together with female education and women's empowerment, as well as legal reforms (May \& Rotenberg, 2020)

Acknowledgements

Does not apply.

Availability of data

The datasets are available from public depositories https://www.statcompiler.com, http://www.wittgensteincentre.org/ dataexplorer, and https://databank.worldbank.org/source/world-development-indicators. 


\section{Competing interests}

The author declares that he has no competing interests.

Received: 8 June 2020 Accepted: 10 August 2020

Published online: 21 September 2020

\section{References}

Bongaarts, J. (1990). The measurement of wanted fertility. Population and Development Review, 16, 487-506.

Bongaarts, J. (1997). The role of family planning programmes in contemporary fertility transitions. In G. Jones, J. Caldwell, R. Douglas, \& R. D'Souza (Eds.), The Continuing Demographic Transition. Oxford: Oxford University Press.

Bongaarts, J. (2008). Fertility transitions in the developing world: Progress or stagnation? Studies in Family Planning, 39(2), $105-110$.

Bongaarts, J. (2011). Can family planning programs reduce high desired family size in sub-saharan Africa? International Perspectives on Sexual and Reproductive Health., 37(4), 209-216.

Bongaarts, J., Cleland, J., Townsend, J., Bertrand, J., \& Das Gupta, M. (2012). Family Planning Programs for the 21st Century: Rationale and Design. New York: Population Council.

Bongaarts, J., \& Hardee, K. (2017). The role of public-sector family planning programs in meeting the demand for contraception in sub-saharan Africa. International Perspectives on Sexual and Reproductive Health, 43(2), 41-50.

Bongaarts \& Hardee (2019). Trends in contraceptive prevalence in sub-Saharan Africa: The roles of family planning programs and education. African Journal of Reproductive Health, 23(3), 96-105.

Caldwell, J., \& Caldwell, P. (1988). Is the Asian family planning program model suited to Africa? Studies in Family Planning, 19(1), 19-28.

Casterline, J., \& El-Zeini, L. (2007). The estimation of unwanted fertility. Demography, 44, 729-774

Casterline, J., \& Sinding, S. (2000). Unmet need for family planning in developing countries and implications for population policy. Population and Development Review, 26(4), 691-723.

Cleland, J. (1994). Different pathways to demographic transition. In F. Graham-Smith (Ed.), Population: the Complex Reality: a Report of the Population Summit of the World's Scientific Academies (229-247). London: Royal Society.

Cleland, J., Phillips, J., Amin, S., \& Kamal, G. (1994). The determinants of reproductive change in Bangladesh: Success in a challenging environment. Washington DC: World Bank.

Cleland, J., \& Lush, L. (1997). Population and policies in Bangladesh, Pakistan. Forum for Applied Research and Public Policy, 12 $46-50$

Cochrane, S. (1979). Fertility and education: What do we really know? Washington DC: Johns Hopkins University Press.

Davis, K. (1945). The world demographic transition. The Annals of the American Academy of Political and Social Science, 237, 1-11.

Davis, K. (1967). Population policy: Will current programs succeed? Science, 158(3802), 730-739.

Demeny, P. (1975). Observations on population policy and population program in Bangladesh. Population and Development Review, 1(2), 307-321.

Debpuur, C., Phillips, J., Jackson, E., Nazzar, A., Ngom, P., \& Binka, F. (2002). The impact of the Navrongo Project on contraceptive knowledge and use, reproductive preferences, and fertility. Studies in Family Planning, 33(2), 141-164.

Diamond, I., Newby, M. \& Varle, S. (1999). Female education and fertility: Examining the links. In C. Bledsoe, J. Casterline, J. Johnson-Kuhn, \& J. Haaga (Eds.), Critical Perspectives on Schooling and Fertility in the Developing World, (23-48). Committee on Population Commission on Behavioral and Social Sciences and Education, National Research Council. Washington, D. C.: National Academy Press.

Freedman, R., \& Berelson, B. (1976). The record of family planning programs. Studies in Family Planning, 7(1), 1-40.

Gaylor, O. (2005). The Demographic transition and the emergence of sustained economic growth. Journal of the European Economic Association, 3(2-3), 494-504

Günther, I., \& Harttgen, K. (2016). Desired fertility and number of children born across time and space. Demography, 53(1), 55-83.

Hadden, K. \& London, B. (1996). Educating girls in the third world. International Journal of Comparative Sociology, 37(1-2), 31-46.

ICF International. (2020). The DHS program STATcompiler. https://www.statcompiler.com. Accessed on 30 April 2020.

Jejeebhoy, S. (1995). Women's education, autonomy, and reproductive behaviour: Experience from developing countries. Oxford: Clarendon Press.

Kirk, D. (1996). Demographic transition theory. Population Studies, 50(3), 361-387.

Kravdal, O. (2002). Education and fertility in Sub-Saharan Africa: Individual and community effects. Demography, 39(2), 233-250.

Kuang, B., \& Brodsky, I. (2016). Global trends in family planning programs, 1999-2014. International Perspectives on Sexual and Reproductive Health, 42(1), 33-44.

Lam, D. (2011). How the world survived the population bomb: Lessons from 50 years of extraordinary demographic history. Demography, 48, 1231-1262

Lee, K., Lush, L., Walt, G., \& Cleland, J. (1998). Family planning policies and programmes in eight low-income countries: A comparative policy analysis. Social Science in Medicine, 47(7), 949-959.

Lightbourne, R. (1987). Reproductive preferences and behavior. In J. Cleland, \& C. Scott (Eds.), The World Fertility Survey, (pp. 838-861). Oxford: Oxford University Press.

Lloyd, C. (2003). Education. In P. Demeny, \& G. McNicoll (Eds.), Encyclopedia of Population, (pp. 278-283). New York: Macmillan

Lutz, W., \& Skirbekk, V. (2014). How education drives demography and knowledge informs projections. In W. Lutz, W. Butz, \& K. Samir (Eds.), World Population and Human Capital in the Twenty-First Century, (pp. 14-38). Oxford: Oxford University Press.

Mauldin, W., \& Ross, J. (1991). Family Planning Programs: Efforts and Results, 1982-89. Studies in Family Planning, 22(6), 350-367.

May, J., \& Rotenberg, S. (2020). A call for better integrated policies to accelerate the fertility decline in sub-Saharan Africa. Studies in Family Planning, 51(2), 193-204.

Murtin, F. (2013). Long-term determinants of the demographic transition,1870-2000. The Review of Economics and Statistics, 95(2), 617-631. 
Notestein, F. (1945). Population: The long view. In T. Schultz (Ed.), Food for the World, (pp. 36-57). Chicago: University of Chicago Press.

Phillips, J., Stinson, W., Bhatia, S., Rahman, M., \& Chakraborty, J. (1982). The demographic impact of the family planning-health services project in Matlab, Bangladesh. Studies in Family Planning, 13(5), 131-140.

Pritchett, L. (1994). Desired fertility and the impact of population policies. Population and Development Review, 20(1), 1-55.

Robinson, W., \& Ross, J. (2007). The global family planning revolution: Three decades of population policies and programs. Washington, DC: World Bank.

Ross, J., \& Smith, E. (2011). Trends in national family planning programs, 1999, 2004 and 2009. International Perspectives on Sexual and Reproductive Health, 37(3), 125-133.

Rutstein, S., \& Rojas, G. (2006). Guide to DHS statistics, Demographic and health surveys, ORC Macro 0. Maryland: Calverton.

Schoumaker, B. (2019). Stalls in fertility transitions in sub-saharan Africa: Revisiting the evidence. studies in family planning, 50(3), 257-277.

Schultz, P. (1994). Human capital, family planning and their effects on population growth. American Economic Review, 84(2), $255-260$.

Singh, S., Darroch, J., \& Ashford, L. (2014). Adding it up the costs and benefits of investing in sexual and reproductive health. New York: Guttmacher Institute.

Summers, L. (1992a). "Investing in all the people." The Pakistan development review,31(4), 367-404.

Summers, L. (1992b). The most influential investment. Scientific American, August 1992,132.

Tietze, C. (1981). Induced abortion: A world review. New York: Population Council.

United Nations, Population Division (2019). World Population prospects: The 2019 revision. New York: United Nations.

Westoff, C. (2010). Desired number of children: 2000-2008, DHS Comparative Reports No. In 25, Calverton. MD: ICF Macro.

Wittgenstein Centre for Demography and Global Human Capital. (2020). Wittgenstein Centre Data Explorer Version 1.2. http://www.wittgensteincentre.org/dataexplorer. Accessed on 3 May 2020

World Bank (1993). Effective family planning programs. Washington DC.: The World Bank.

World Bank. (2020). World Development indicators. https://databank.worldbank.org/source/world-development-indicators. Accessed on May 3, 2020.

\section{Publisher's Note}

Springer Nature remains neutral with regard to jurisdictional claims in published maps and institutional affiliations.

\section{Submit your manuscript to a SpringerOpen ${ }^{\circ}$ journal and benefit from:}

- Convenient online submission

- Rigorous peer review

- Open access: articles freely available online

- High visibility within the field

- Retaining the copyright to your article

Submit your next manuscript at $\boldsymbol{\nabla}$ springeropen.com 